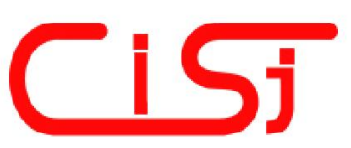

\title{
A FUZZY PAY-OFF METHOD FOR REAL OPTION VALUATION IN DETERMINATION OF MINING ENTERPRISE VALUE
}

\author{
Marian Turek, Adam Sojda \\ Faculty of Organisation and Management, Silesian University of Technology, \\ Roosevelta 26 Str., 41-800 Zabrze, Poland \\ e-mail: marian.turek@polsl.pl, adam.sojda@polsl.pl
}

\begin{abstract}
The article presents the use of real options in determination of mining enterprise value. The value estimation is based on discounted cash flow method. The adoption of fuzzy numbers allows introducing a risk aspect to the known method of determination of enterprise value. A classic discounted cash flow method uses one scenario on the basis of which one value is determined. The method presented is grounded on three scenarios: optimistic, the most probable, pessimistic. On this basis the values defining a fuzzy number are indicated. Algorithm of this defuzzification, based on the idea of real options enables indicating a concrete value. Copyright (C) Research Institute for Intelligent Computer Systems, 2014. All rights reserved.
\end{abstract}

Keywords: enterprise value, pay-off method, real option, fuzzy numbers.

\section{INTRODUCTION}

The first decade of XXI century will be remembered as a period of crises of a global character. It is a result of strong connection of individual economies. Financial institutions as well as governments of the particular countries tried to take decisions aimed at stopping the crisis development. Economic crisis concerned each state in a different way in the United States of North America, in Ireland a sudden fall of economic indicators was observed, in other countries economic slowdown occurred. Undoubtedly, this situation contributed to the interest increase in the methods allowing risk inclusion. In the periods of economic growth the forecasts may be determined as point predictions. However, in case of crisis, when it is known that the future cannot be predicted 'easily', it is rational to build interval predictions. Interval prediction provides additional information for a decision maker concerning the risk and threats that may appear. In the time of crisis interval forecasting should replace point forecasting. It is necessary to introduce the methods that include risk.

\section{RISK}

Risk is the phenomena of an objective character. It commonly occurs in the economic activity. However, it does not relate to each area in the same extent. Risk is generated by the necessity of predicting future. The complexity of reality, not only the economic one, causes that the result of activity does not only depend on our decision but is also affected by other factors. In the economic activity one should know how to measure risk and also identify its sources.

The definition of "risk" may be considered in an objective and subjective aspect. The objective risk is meant as a relative deviation of real loss from the expected loss. Such definition of risk allows determination of risk measure as a measure of dispersion, e.g. standard deviation, variation coefficient. Another measure may be also considered as a maximum probable deviation of real value from the expected value. These risk measures may be applied with the assumption about the knowledge of real loss distribution or also in the situation when the law of large numbers applies (we obtain an accordingly large number of statistical data). The subjective risk concerns the uncertainty based on the individual experiences. "Subjective risk is an individual estimate of possibility of occurrence of a certain result".

In effect, risk is an ambiguous notion and in order to conduct its measurement, one should possess adequate statistical information. They enable determination of risk measure on the basis of past activities. The possibility of using such measure for past activities is linked to fulfilling the basic forecast rule which assumes that the forecast model, being built for a certain period, will still be up-to-date. In case when the economic system is not affected by 
crisis there may be risk measures used based on the statistical measures. In the crisis situation the economic state is changing in an unpredictable way in terms of intensity, there are directions of changes possible to predict - expected value decrease. In practice, risk measurement may be conducted through experts' participation who can estimate, indicate some amounts as well as determine the type of their distribution. There may also be many different scenarios generated and on their basis, statistical measures applied. Nevertheless, the increases of options solved are generated. In PERT method there may the three realization scenarios used for a particular activity. The scenarios are: the most optimistic, modal - occurring most often and the most pessimistic. Accordingly, there be may such a method sought which, in calculating the company value, includes the analogical scenarios

\section{REAL OPTION}

The term of real option was introduced to literature by S. Mayers in 1997. This term relates to the conception of application of financial option theory in non-financial investment pricing. This conception is characteristic for embedded decision flexibility. It allows learning in the subsequent stages of investment process. Real option may be understood as a system and integrated approach that enables real assets valuation. Valuation takes place in a dynamic environment that is specific for high uncertainty. At the same time the output of finance theory, management sciences, decision-making theory, statistics or econometric modeling is used. Real options find their use in decision-making situations when there is a possibility to choose a direction, type and moment of making a decision. They are used in cases in which an investment project or a company is valued or company strategy is designed. There are at least four conceptions of real options related to: valuation model, way of thinking, decision-making process, and organization model. The first works on real options concerning the problems of asset pricing using the tools known from financial markets. The examples appear starting from the simplest model related to the Black-Scholes model, binomial model or also more advanced ones, e.g. Margrabe Model.

The following options may be distinguished. Waiting-to-invest option is an option that creates a possibility to delay investment in time. For example, the enterprise possessing rights to conduct exploitation of some deposits waits for production launch in the deposit until the moment when the price of the resource obtained is high enough in order to provide a return on the investment. Abandon, discontinue option is an option allowing continuation cease of an investment project. Alter operating scale is an option that enables change in the scale of activity. The change consists in increasing or decreasing the scale of project. This option may be considered in case when the company is going to sell a some part of assets. Stage investment, compound option is a possibility to divide the undertaking into stages. Conduction of the subsequent stages depends on the results of the previous stages. Growth option concerns such undertakings in which additional possibilities are brought for the company, e.g. new products, access to new markets.

\section{FUZZY NUMBERS}

An attempt to capture and describe a fragment of the surrounding reality by the use of only one value is very often insufficient. The attempt to capture mathematically the fuzziness of problems allows using the 'approximately' category instead of the category: 'precisely'. The use of fuzzy numbers makes it possible to implement dispersion as an additional element, creating a fuzzy number.

Definition 1. A fuzzy set A in a certain nonempty space $\mathrm{X}$ is called a set of pairs

$$
\mathbf{A}=\{(x, A(x) ; x \in \mathbf{X})\}
$$

in which $A(x): \mathrm{X} \rightarrow[0,1]$ is the membership function of the fuzzy set A. This function, for each $\mathrm{x} \in \mathrm{X}$ determines the degree of its membership to the fuzzy set A. The three basic cases are distinguished:

- full membership of the element $\mathrm{x}$ to the fuzzy set, in such case $A(X)=1$,

- no membership of the element to the fuzzy set, in such case $A(X)=0$,

- partial membership of the element to the fuzzy set, in such case $0<A(X)<1$.

A fuzzy number may also be defined by providing the membership function.

Definition 2. A fuzzy number A we call an any fuzzy set determined in the space of real numbers $R$ by the use of a membership function

$$
A(x)= \begin{cases}0 & \text { for } x \leq a \\ f_{A}(x) & \text { for } a \leq x \leq b \\ 1 & \text { for } b \leq x \leq c \\ g_{A}(z) & \text { for } c \leq x \leq d \\ 0 & \text { for } d \leq x\end{cases}
$$

where the function $f_{A}, g_{A}$ are continuous functions with $f_{A}$ growing in the interval $[a, b]$ and $f_{A}$ is decreasing in the interval $[c, d]$. It is accepted for the values $a, d$ to reach infinity. 
Definition 3. The membership function of triangle class $t$ is defined in the following way:

$$
A(x)=\left\{\begin{array}{rr}
1-\frac{a-x}{\alpha} & \text { for } a-\alpha \leq x \leq a \\
1-\frac{x-a}{\beta} & \text { for } a \leq x \leq a+\beta \\
0 & \text { besides }
\end{array}\right.
$$

The fuzzy number of membership $t$ can be written as $\mathrm{A}=(\mathrm{a}, \alpha, \beta)$.

The transformation of a fuzzy number to a real number is performed on the basis of the operation of sharpening and one of the ways is the pay-off method described in definition 4.

Definition 4. Pay-off method also calculates the real value ROV by using the following formula:

$$
R O V=\frac{\int_{0}^{+\infty} A(x) d x}{\int_{-\infty}^{+\infty} A(x) d x} E\left(A_{+}\right),
$$

where:

- $\int_{-\infty}^{+\infty} A(x) d x$ is the area below the membership function,

- $\int_{0}^{+\infty} A(x) d x$ is the area below the membership function for positive values.

The value $\mathrm{E}\left(A_{+}\right)$is determined from the formula and is a conditional expected value for positive values:

$$
E\left(A_{+}\right)= \begin{cases}a+\frac{\beta-\alpha}{6} & , a-\alpha>0 \\ \frac{(\alpha-a)^{3}}{6 \alpha^{2}}+a+\frac{\beta-\alpha}{6} & , a-\alpha<0<a, \\ \frac{(a+\beta)^{3}}{6 \beta^{2}} & , a<0<a+\beta \\ 0 & , a+\beta<0\end{cases}
$$

Below in Fig. 1 there is triangular fuzzy number presented.

The value ROV indicated according to formula (4) is a value obtained on the basis of three values calculated. The area indicated by the triangle comprising the triangular value, the area indicated by a part of triangular value for positive values $\mathrm{x}$, expected value for positive values according to the formula (5). The expected value $\mathrm{E}(\mathrm{V}+)$ in some cases does not include complete information regarding risk, for $a<0$ there is no value $\alpha$. Additionally, this value is calibrated by a relation of the area for positive value to the total area. It causes that in the value ROV the information possessed about the values is included.

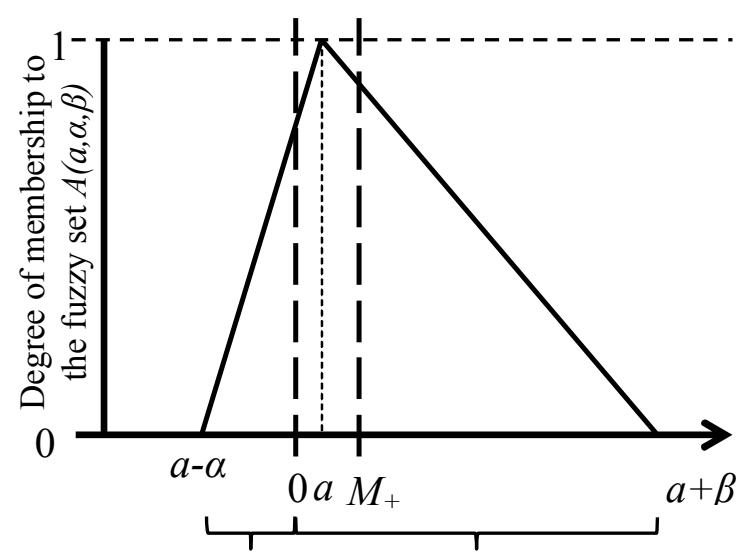

Area

$\mathrm{x}<0 \quad$ marked average value

Fig. 1 - Triangular fuzzy number $\boldsymbol{A}$ with a marked average value $M$.

Introduction of the fuzzy numbers allows gathering more complex structures in the form of one 'number'. The transformation of a fuzzy number to a real one is also possible. The pay-off method suggested ascribes real value to the fuzzy number additionally taking into consideration the position of the number in relation to the value that equals 0 . This additional modification has a particular significance for the use of this method in the context of company value

\section{COMPANY VALUE}

The definition of value has many meanings and it may mean something else for everyone. In the interpersonal relations, we very often deal with own, subjective estimation of value. In case of company being in the relations with other companies, the need for introducing an unambiguous definition of value as well as the way of its measurement is very desired. As there is no conformity about the equivalence of the word "value", also from the point of view of company strategy many meanings of this word appear. I most cases value is understood as how much something is worth for us in a material respect. We define value as "everything what is valuable and worth desire" or as "a feature of a thing being able to define in monetary equivalent or other legal tender".

The sources of company value should be searched in its capital. Company, spending capital 
on particular economic undertakings, expects a certain return on invested capital. The capital and decisions about its use must support the value sources. The application of the "capital" definition is not disposed of ambiguous features, we deal with definitions of the following capital: intellectual, social, material, cultural etc.

In the categories of company, capital may be treated as:

- wealth needed for further production,

- result of some part of production process meant for further production,

- subject of a loan.

Capital and value are inseparably connected and penetrate each other. The capital value is treated as a monetary expression of the current market value of the company. There are many definitions for the notion of company value $[5,6]$ e.g.: economic value, value in use, book value, reproduction value, market value, fair value, goodwill value.

\subsection{INVESTMENT VALUE}

The basic source of company value creation is investment. This notion is also accompanied by the ambiguity. On the one hand, investment may be perceived from the point of cash flows' view (money movements) and on the other hand, investment has its material dimension resulting from a material effect in the effect of conducting investment. It is also possible to capture the mutual features which are: outlay, benefit, time and risk.

One of the methods of investment evaluation is NPV method using cash flows generated by investment:

$$
N P V=\sum_{t=1}^{n} \frac{C F_{t}}{(1+i)^{t}},
$$

where $N P V$ - net present value, $C F_{t}$ - cash flows in the period $t=1,2, . ., \mathrm{n}, i-$ discount rate.

\subsection{INVESTMENT VALUE}

Analogically to a single investment, the company performance may be evaluated taking into account cash flows as well as residual value generated by the company

$$
V=\sum_{t=1}^{n} \frac{F C F_{t}}{(1+W A C C)^{t}}+\frac{R V_{n}}{(1+W A C C)^{n}},
$$

where $V$ - company value, $F C F_{t}$ - net cash flows in the period t, WACC - weighted average cost of capital used for company activity financing in the period $t=1,2, . ., n, n$ - number of years for which the cash flows are estimated (number of years included in the forecast), $R V_{n}$-residual value obtained by the company after the ending of period $n$.

The residual value is indicated from the Gordon formula or it is assumed that is equal zero.

The presented way of value indication implies the necessity of presenting a concrete value of cash flow in the subsequent periods of company performance. In this depiction we obtain one certain value. Among the four pillars of investment the most risky one is omitted. Therefore, searching for new ways of estimation regarding risk is very important in case of conducting activity, especially an investment activity.

Company value is affected by many factors. Let us analyze the most important ones mentioned in the formula. The changing value of money in time is included in determining the current value. For this purpose cash flows are discounted. A discounting factor is based on the weighted average cost of capital. Cost of capital depends on a capital structure in the enterprise, on an interest rate that the capital is borrowed by the company. The interest rate is a sum of two components. One of them is the bank's profit margin, the other one is the interest rate accepted in settlements between the banks. The latter one depends on a general financial condition of the banks and economy. The value of cash flows contains many factors and on one hand these are revenues connected with sales, costs and investment on the other hand. Sales revenues in the simplest case depend on the production volume and price. However, the costs are generated by remuneration, raw material, energy, taxes and depreciation. In case of renewable energy sources such as crude oil, natural gas it may be noticed that in the way of regulation connected with production volume there is a possibility to adjust the price. The structure and way of enterprise management has an undeniable influence on the costs of its functioning. Nevertheless, it should be noticed that the specificity of some industries forces a necessity to bear high costs. These are usually fixed costs, linked to providing safety, a possibility to conduct the production process itself. Hard coal mining is such an industry. In case of hard coal mining, coal is excavated on deeper layers what causes that the costs of production are rising. The ground infrastructure remains unchanged and the underground area is spreading both in terms of depth and length. Miners and coal have to be transported from further places. The time of effective work on production post is decreasing. The process of conducting hard coal excavation is an investment process, each mining field is a new investment. The investment requires capital, therefore a high share of debt capital occurs. 
In the works $[2,3]$ it is shown how, by using the formula (4) and fuzzy pay-off method, one can obtain the evaluation of investment projects. It seems natural to apply this method for company value estimation on the basis of formula (7).

\section{IT MANAGEMENT SYSTEMS}

The conception of enterprise management through increasing its value requires a permanent control of the external and internal factors affecting the company value. Effective management in this area is not possible without the support of IT management systems. These systems gather and analyze data from all divisions and present them in a form appropriate for the particular divisions. In case of using the fuzzy pay-off method in estimating the company value it is necessary to know the future values concerning both the costs and revenues obtained in different scenarios ( 3 scenarios). Various company units prepare information about the future values. The possibilities of selling the production in future should be assessed. Next, the production size and its cost should be planned. One should also pay attention to the relation between the price and production.

During the process of works on scenarios formulation strategic and operational management should be combined. It is important to include the customer needs as well as to take care of proper production resources. During the works on scenarios there should be information used about human resources, payroll, material management and production planning. The aforementioned elements are the components of most IT management systems.

Depending on the degree of IT tools use in the enterprise the application of this method may be integrated with the system to a bigger or lesser extent. During the scenarios development the work with applications takes place with the use of the following applications:

- enterprise resource planning (ERP) - used to plan, manage, control the business process across multiple locations,

- supply chain management (SCM) - enables more efficient management of the supply chain, support of material management, allows estimating the future costs,

- customer relationship management (CRM) system useful in determining the size of future production,

- knowledge management system (KMS) - allows creating the knowledge base that may additionally help in building scenarios. Thanks to this system a greater automation during scenario development is possible. It shortens the time and enables a quicker reaction to the changing conditions.
The use of pay-off method seems simple if the company is able to build the reliable scenarios.

\section{EXAMPLES OF APPLICATION}

Considerations regarding risk lead to a conclusion that in case of a crisis, classic measures of risk based on the measures of variability cannot be used. Analogically to network programming, taking risk into consideration requires at least three scenarios. Various ways of valuation and understanding the company value make it possible to select such method for which the use of scenario options should not be difficult. Fuzzy numbers allow processing the entirety of information passed by the indicated scenario that is taking risk into consideration. In the examples below the connection of risk, company value and fuzzy numbers is presented.

\subsection{EXAMPLE 1}

Let us assume that a particular enterprise was valued using the pay-off method and a fuzzy number ROV that equaled $(400,200,100)$ was received and the determined value amounted to 383.33. If each of the values determining the number $\mathrm{V}$ is decreased by 300 , then a new value of the number ROV' is equal to $(100,200,100)$. The value calculated from the formula (4) equals 72.92. The value is not lower than the previous one by 300 , it differs from it by around $19 \%$.

\subsection{EXAMPLE 2}

The method proposed requires indicating the company value for three scenarios. Below there is a dependence analysis of ROV presented on a change of the particular parameters indicating fuzzy number A. In Fig. 2 there is a dependence of $\operatorname{ROV}(a)$ presented, in Fig. 3 dependence $\operatorname{ROV}(\alpha)$ for $a=-1$, in Fig. 4 dependence $\operatorname{ROV}(\alpha)$ for $a=1$, in Fig. 5 dependence $\operatorname{ROV}(\beta)$ for $\mathrm{a}=-1$ and in fig. $6 \operatorname{ROV}(\beta)$ for $\mathrm{a}=1$.

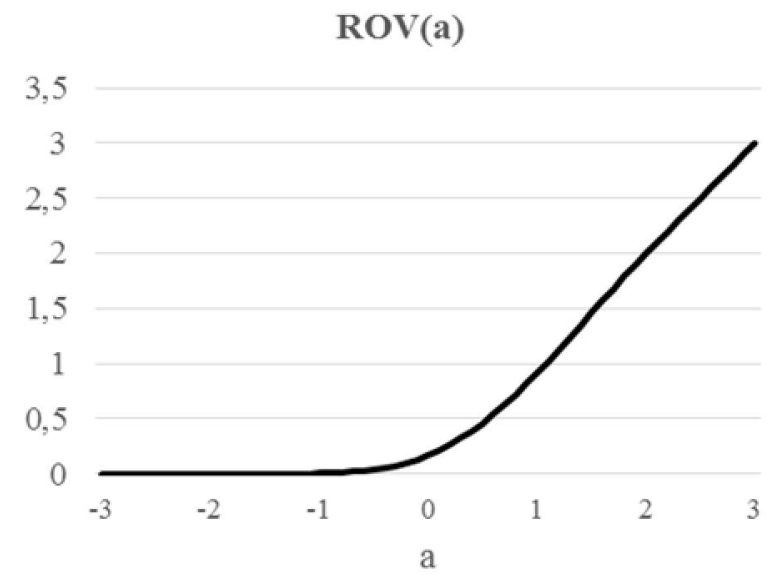

Fig 2 - Graph $\operatorname{ROV}(a)$ for changing values $a$ in the range from -3 to 3 for triangular number $\mathrm{A}(a, 2,2)$. 
The graph of function ROV(a) consists of a combination of two linear function and polynomial of $5 \mathrm{rd}$ degree. For values a lower than 2 the function $\mathrm{ROV}(\mathrm{a})$ takes the value of 0 . For values a more than 4 a linear dependence occurs.

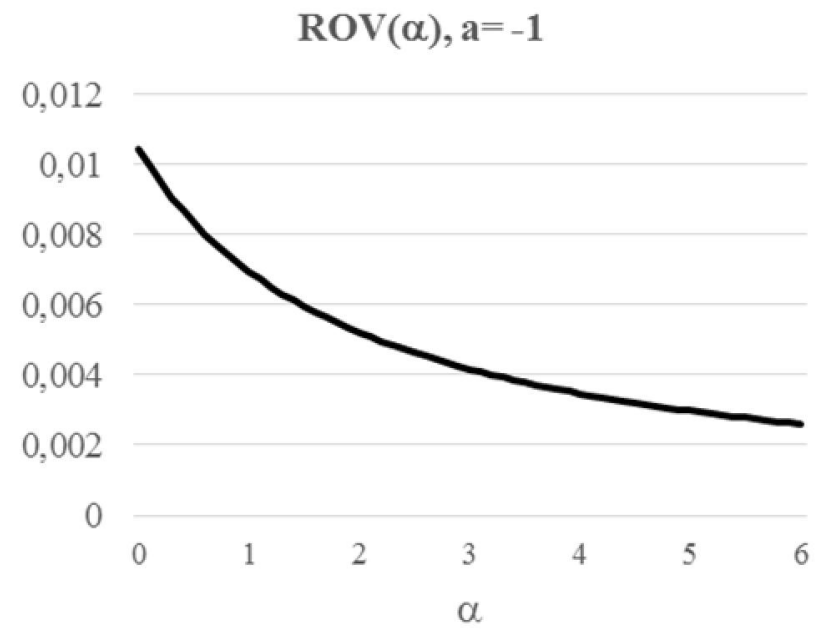

Fig 3 - Graph $\operatorname{ROV}(\alpha)$ for changing values $\alpha$ in the range from 0 to 6 for triangular number

$$
\mathrm{A}(-1, \alpha, 2) \text {. }
$$

The graph of function $\operatorname{ROV}(a)$ consists polynomials of $5 \mathrm{rd}$ degree

$$
\operatorname{ROV}(\alpha), a=1
$$

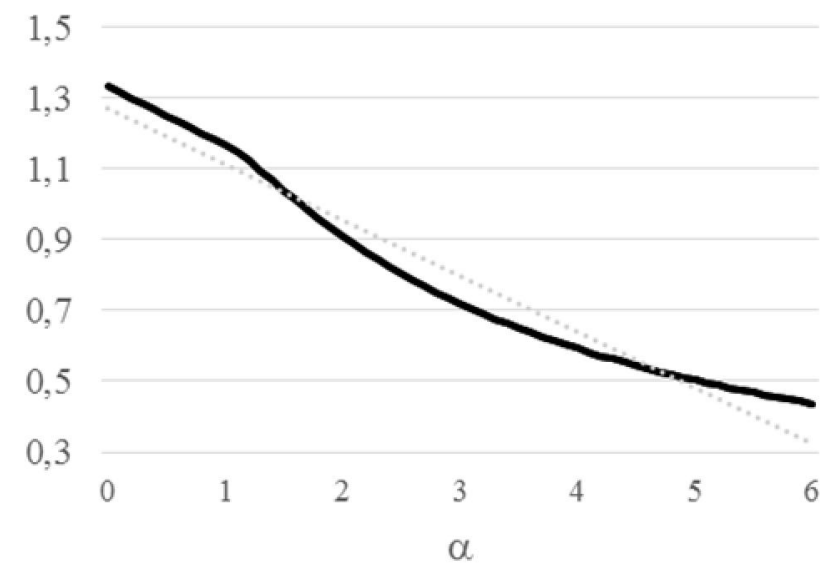

Fig 4 - Graph $\operatorname{ROV}(\alpha)$ for changing values $\alpha$ in the range from 0 to 6 for triangular number $A(1, \alpha, 2)$.

The graph of function ROV(a) consists of a combination of linear function and polynomial of 5rd degree.

The graph of function $\operatorname{ROV}(\beta)$ consists of a combination of linear function and polynomial of 5 rd degree.

The graph of function $\operatorname{ROV}(\beta)$ for $a=1$ consists of a polynomial of 5rd degree (Fig.6).

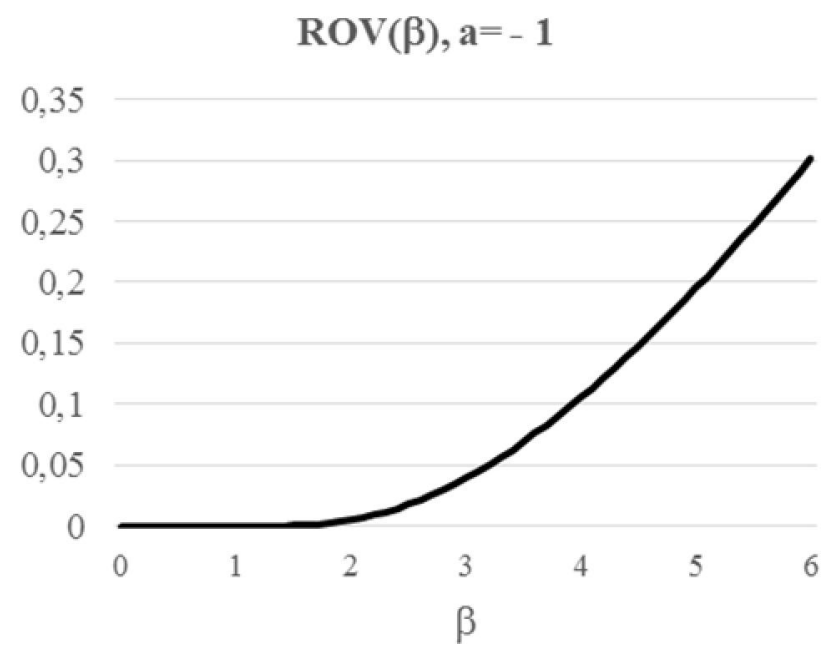

Fig 5 - Graph $\operatorname{ROV}(\beta)$ for changing values $\beta$ in the range from 0 to 6 for triangular number $\mathrm{A}(-1,2, \boldsymbol{\beta})$.

\section{$\operatorname{ROV}(\beta), a=1$}

2

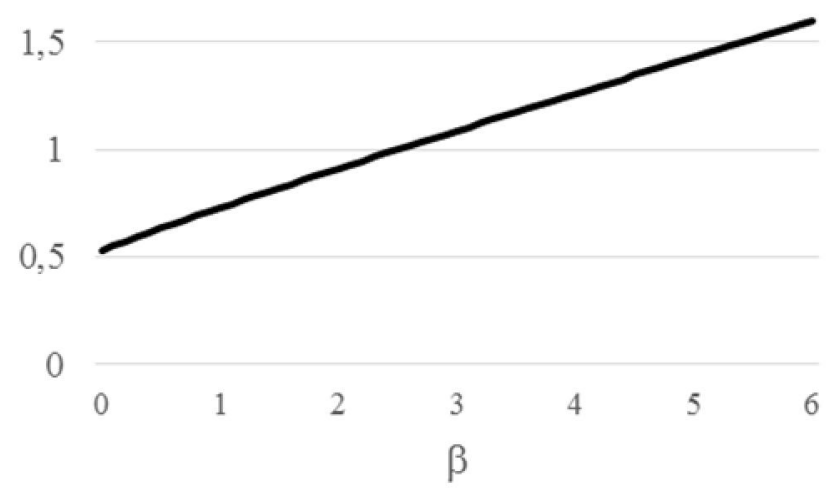

Fig 6 - Graph $\operatorname{ROV}(\beta)$ for changing values $\beta$ in the range from 0 to 6 for triangular number $A(1,2, \beta)$.

\subsection{EXAMPLE 3}

For a given value of WACC three scenarios are assumed for which the values of cash flows were determined and the residual value was equal zero. The Good, Base and Bad scenario correspond to the cash flows determined in case of the following situations: the most advantageous, the most probable and the worst possible. The grounds for the base scenario was the value of cash flows that was actually estimated in one mining enterprise. The value for the Good and Bad scenario was determined by expert consultations. It was assumed that the flows in the Good scenario will be by $20 \%$ higher than in the Base scenario. WACC $12 \%$, residual value is zero [7, 8]. In Table 1 the values of those cash flows for the particular years are presented. 
Table 1. FCF for The Good, Base and Bad scenario in million PLN.

\begin{tabular}{|c|r|r|r|r|c|}
\hline $\mathbf{t}$ & \multicolumn{1}{|c|}{$\mathbf{1}$} & \multicolumn{1}{c|}{$\mathbf{3}$} & \multicolumn{1}{c|}{$\mathbf{5}$} & $\mathbf{5}$ \\
\hline $\mathrm{FCF}_{\text {Good }}$ & 360 & 360 & 420 & 480 & 600 \\
\hline $\mathrm{FCF}_{\text {Base }}$ & 300 & 300 & 350 & 400 & 500 \\
\hline $\mathrm{FCF}_{\text {Bad }}$ & -500 & -400 & 50 & 100 & 150 \\
\hline \\
$\mathrm{V}_{\text {Good }}=2908, \mathrm{~V}_{\text {Base }}=2424, \mathrm{~V}_{\text {Bad }}=-509$
\end{tabular}

The fuzzy number was received presenting the value $\mathrm{V}$ of the company in the form of: A(2 424, 2 932, 285). It makes it possible to determine the value of ROV that is equal to 1967 million PLN based on the formulas (6) and (7).

\section{CONCLUSIONS}

Thanks to the use of fuzzy numbers, in an easy way it is possible to include additional information in the form of two options determining the scale of variability of a certain value. It allows including the aspect of risk in the value estimation. From the arithmetic point of view the implemented change is not very complicated. The value $\mathrm{V}$ for the particular scenarios is calculated in a traditional way. Additionally, only the value should be indicated which is not a very complex arithmetic task. Therefore, the presented method is a supplement to the classic methods. And the sharpened value $\mathrm{V}$ includes the information about variability - risk.

\section{ACKNOWLEDGEMENTS}

The work was elaborated within the frames of research project realization no. N N524 341640 "Method of value estimation in a hard coal mine" financed by the Polish National Science Center.

\section{REFERENCES}

[1] C. Carlson, R. Fuller, A fuzzy approach to real option valuation, Fuzzy Sets and Systems, (139) 2 (2003), pp. 297-312.

[2] M. Collan, R. Fuller, J. Mezei, A fuzzy pay-off method for real option valuation, Journal of Applied Mathematic and Decision Sciences, Vol. 2009, 2009, Article ID 2238196, 14 pages, doi: $10.1155 / 2055 / 238196$.

[3] M. Collan, J. Kinnunen, A procedure for the rapid pre-acquisition screening of target companies using the pay-off method for real option valuation, Journal of Real Option Strategies, (4) 1 (2011), pp. 117-141.
[4] A. Keswani, M. Shackleton, How real option disinvestment flexibility augments project NPV, European Journal of Operational Research, (168) 1 (2006), pp. 240-252.

[5] I. Jonek-Kowalska, A. Michalak, Ryzyko, Koszt Kapitatu $i$ Efektywność $w$ Procesie Finansowania Inwestycji Rozwojowych w Górnictwie Węla Kamiennego, PWN, Warszawa 2012, p. 109. (in Polish)

[6] W. Rudny, Opcje Rzeczowe w Procesie Tworzenia Wartości Przedsiębiorstwa, Wydawnictwo Akademii Ekonomicznej w Katowicach, Katowice, 2009. (in Polish)

[7] M. Turek, Modele Finansowania Działalności Operacyjnej Przedsiębiorstw Górniczych, GIG Katowice, 2011

[8] M. Turek, A. Sojda, Determination of enterprise value by using the fuzzy pay-off method for real option valuation, in Proceedings of the $7^{\text {th }}$ IEEE International Conference on Intelligent Data Acquisition and Advanced Computing Systems (IDAACS'2013), Berlin, Germany, (12-14 September 2013), pp. 597-600.

[9] L. Zadeh, Fuzzy Sets, Information and Control, (8) (1965), pp. 338-353.

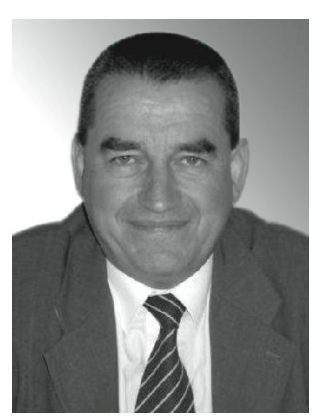

Marian Turek - full professor, dean at the Faculty of Organization and Management at the Silesian University of Technology, an author of over two hundred publications on economics and management in hard coal mining industry. The scientific achievements are enriched by numerous scientific-research projects conducted in Polish and foreign enterprises as well as with a long-term experience in mining enterprises management.

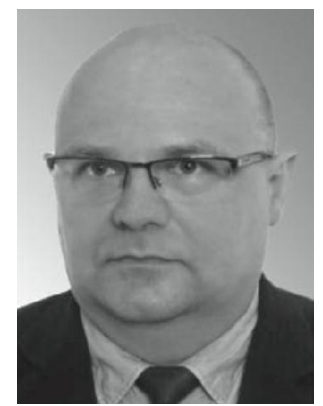

Adam Sojda - lecturer at the Faculty of Organization and Management at the Silesian University of Technology. An author of several dozen publications on operations research, evolutionary methods, economy and management. An executor in many scientificresearch projects conducted in 